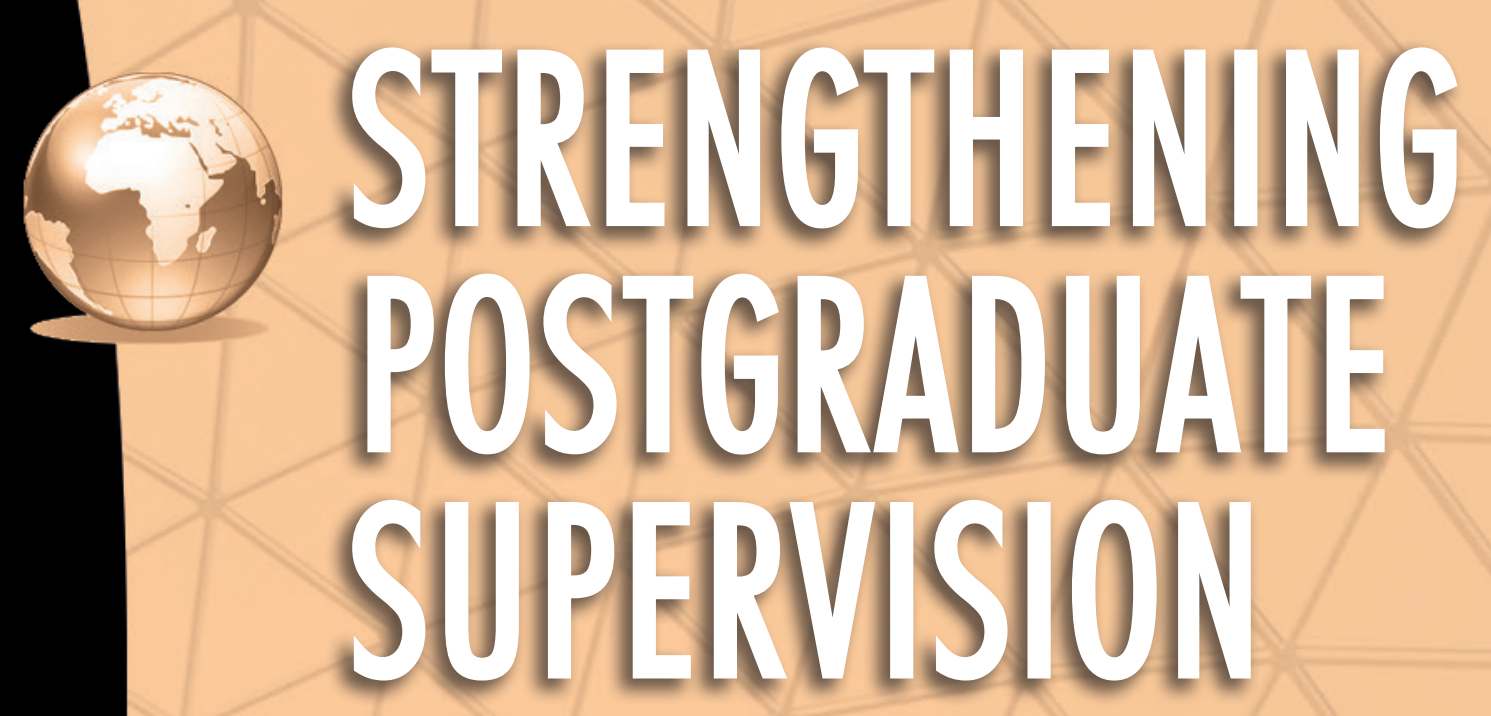

EDIORS

SIOUX MOKENNA

JENNY CLARENCE-FINCHAM

CHRISSIE BOUGHEY

HARRY WELS

HENK VAN DEN HEUVEL

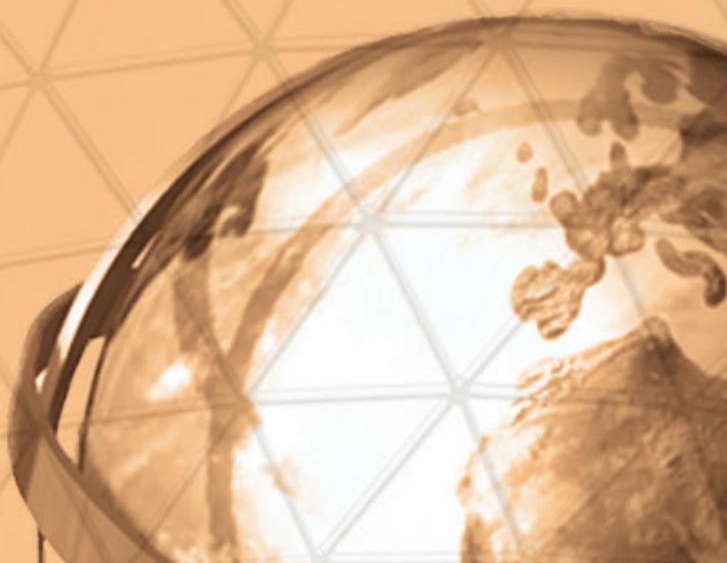




\title{
LISTENING TO OUR CONTEXTS
}

\author{
Chrissie Boughey, Rhodes University \\ Henk van den Heuvel and \\ Harry Wels, Vriie Universiteit Amsterdam
}

The supervision of postgraduate research can be a particularly challenging form of teaching in any context, as the vast literature on postgraduate education reveals (see for instance Motshoane and McKenna, 2014). The journey towards the production of a thesis or dissertation is a lengthy one and involves not only the meeting of two minds in pursuit of an intellectual project but also the coming together of two individuals who may also have very different modes of engaging with others based on their own personal characteristics and preferences as well as on social and cultural differences (Moses 1984). When that journey is undertaken in a context marked by social difference and inequality and where, at the same time, the rewards related to the journey are 'high stakes', then supervision becomes even more difficult to negotiate for both students and academics. For students, obtaining the degree is of utmost importance; for supervisors, academic reputation, performance in terms of outputs (numbers of graduates) and financial incentives are often at stake.

The supervision explored in this book all took place in South Africa, a context which continues to be marked by great inequities at many levels in the higher education system. In 1994, the newly elected democratic government inherited a system fractured along numerous lines. One of the first fractures related to social group with institutions of higher education designated for black, white, Coloured and Indian students. Sometimes institutions were separated only by a fence but differences in the allocation of funding meant that those intended for white social groups were often of a completely different order to their sister institutions intended for black students. A second divide related to distinctions between universities and technikons, the latter being vocationally oriented institutions generally focusing on diploma-level 
programmes with the former offering mainly professional and formative degrees. Geographical location also played a part in shaping the character of an institution with some located in deeply rural areas whilst others, generally those intended for white social groups, were to be found in choice positions in the largest cities. A final major divide was that of the language of learning and teaching. Under apartheid both English and Afrikaans were used as languages of learning and teaching in higher education, a practice which required the conscious development of Afrikaans as an academic language. These linguistic differences contributed to social, cultural and political differences in both staff and student bodies.

These fractures led to enormous disparities in the conditions for research and postgraduate supervision. Essentially, the historically black institutions were established to produce workers for the apartheid regime - teachers, nurses, civil servants and public administrators. The programmes they offered were not intended to develop critical thought, although black institutions were indeed rich sources of intellectualism, a phenomenon that developed in spite of the attempts of the apartheid planners to control criticality. The funding allocated to black universities was not sufficient to support research and postgraduate study, however, with the result that capacity to conduct research was not developed in a consistent manner. Libraries were ill stocked, laboratory facilities were badly resourced and the structures necessary to support black researchers' pursuit for funding were generally absent. To a small extent, the technikons were funded for research provided this was applied and had a demonstrable use value. Historically white universities, on the other hand, were resourced for research and, over the apartheid era, built capacity across the disciplines which has served them well in the years since the shift to democracy.

\section{POLICY POST 1994 AND ITS IMPACTS}

From 1994 onwards, a wealth of policy work was directed at the 'transformation' of higher education in order to develop a system which would provide quality education for all. Early policy documents (see, for example, the National Commission for Higher Education, 1996) identified 'massification' as a strategy to achieve greater equity. In 1994, headcounts at all South African institutions of higher education numbered just over 500000 students with 70\% of these in institutions designated 'universities' and the remaining 30\% in technikons (Cooper and Subotsky, 2001:12). As might be expected in a country emerging from an iniquitous regime, participation rates of the different social groups were also heavily skewed in favour of white students.

In the years since the first democratic election, headcounts have doubled without a concomitant improvement in the participation rates of black students. By 2013, 
participation rates of the 18 - to 24 -year-old cohort stood at $16 \%$ for black African students and $15 \%$ for Coloured students in comparison to $49 \%$ for Indian and $55 \%$ for white students respectively (CHE, 2013). Since 2007, a number of cohort analyses have problematised these participation rates even further showing that, regardless of the institution at which they are enrolled, the programme of study (i.e. diploma or degree) or the subject area, black students fare less well across the board in comparison to their white counterparts in terms of success, graduation and throughput rates (see, for example, Scott, Yeld and Hendry, 2007; CHE, 2013). The impact of poor performance data on postgraduate study is not hard to identify. Not only are black South Africans less likely to access higher education, they are also less likely to graduate, to graduate well and, thus, to proceed to do postgraduate work.

Close analysis shows differences in the choices made by black student as they entered higher education. From 1994, all institutions, regardless of their former designation, were open to students from all social groups. As Cooper and Subotsky's (2001) work has shown, as institutions of higher education opened their doors to all in the 1990s, black students' preferences for vocational, 'work-ready' qualifications, perceived to provide access to the material wealth long denied to black social groups, saw large numbers seeking enrolments in the technikons as opposed to the traditional universities. Black students with scores on the school-leaving examinations which allowed entrance to the historically white institutions abandoned those historically designated for their social groups. The late 1990s, therefore, saw many historically black institutions, and particularly the traditional universities located in rural areas, suffering steep falls in enrolments which then impacted on their finances and, significantly, their morale. These trends have continued to this day although the deterioration of the school system since 1994 has seen many black students only achieving a level of performance on the school-leaving examination which will allow them access to diploma- rather than degree-level study.

As the historically white institutions have sought to 'transform' following the shift to democracy (see for instance Kamsteeg, 2011 ), the need to change the demographics of the academic staff as well as the student body has been high on the agenda. The demand for black academics, and particularly academics with sound research profiles, far outstrips supply and it has become commonplace for highly resourced institutions to 'poach' intellectuals from less well-resourced institutions. Such 'poaching' does not only involve the offer of higher salaries but also resources for these individuals to continue to build and strengthen their research capacity. This phenomenon is fostered by higher education funding policies which are 'incentive 


\section{STRENGTHENING POSTGRADUATE SUPERVISION}

driven' (MoE, 2004) and which reward institutions for research outputs counted in the form of units.

One of the most obvious results of these funding policies has been the placement of key agents responsible for driving a research agenda at institutional level, not necessarily for intellectual gains, but for the financial gains which accrue from 'increasing productivity'. As Deputy Vice Chancellors and Deans for research and development have been appointed at institutions across the system, so too have structures been established in order to drive research productivity and development. These structures include research offices and research policies which, more often than not, reward individuals financially for research outputs. As a result, discourses privileging research have strengthened at South African universities in the last 10 to 15 years because of funding policies. At the same time, efforts to improve teaching and learning at undergraduate level have not borne fruit, as the cohort analyses indicated above have shown. All this means that access to postgraduate education continues to be skewed by the performance of the system, a phenomenon which is then exacerbated by the need for many black graduates to move into the world of work upon completing their undergraduate qualifications in order to earn income to support their families who often continue to be afflicted by dire poverty. This then means that the demographics of those involved in postgraduate study do not reflect those of the general population. All this has profound implications for supervision and, in particular, for the need for black South Africans who do succeed in climbing the academic ladder to be supported as they strive to complete postgraduate qualifications.

Yet more developments in the policy arena have impacted on the skewed character of postgraduate provision in South Africa. In the early 2000s, a massive project intended to reform the entire system was undertaken thanks to the development of the National Plan for Higher Education (DoE, 2001a). This process saw the identification of three 'institutional types': the traditional university, the university of technology developed from the former technikon, and the comprehensive university intended to offer a mix of traditional academic and vocational programmes. This 'sizing and shaping' of the South African higher education system in an effort to bring about greater equity saw a reduction in the total number of institutions from 36 to 23 through a series of mergers and incorporations (DoE, 2001 b), although, as we have already shown, enrolments have grown.

The identification of institutional types in the National Plan was then fostered by a quality assurance project (CHE, 2002) which, in drawing on the notion of quality as 'fitness for and of purpose' encouraged institutions to identify an institutional niche 
for themselves (i.e. a purpose) which could then be driven by internal arrangements for quality assurance. Initial attempts to 'size and shape' the system had included a plan for some institutions to be focused on undergraduate teaching with only limited capacity for research and postgraduate study (DoE, 2001a). This was, however, resisted across the sector in the name of equality and, as we have indicated above, countered by a new funding formula (DoE, 2004) which provided substantial financial rewards for research outputs in the form of subsidy for postgraduate graduations and publications. To all intents and purposes, therefore, all South African universities have sought to develop research capacity since the early 2000 s with varying degrees of success.

Other policy work has focused on the development of a Higher Education Qualifications Sub-Framework (HEQSF) (MoE, 2012), which went through many reiterations before its finalisation in 2012 . The qualification framework is mentioned here not only because it attempts to delineate the development of research capacity by specifying a research component in qualifications from the Honours degree upwards, but also because of the inclusion of 'professional' qualifications at master's and doctoral levels. The acknowledgement of these qualifications signifies more than a formal qualifications type since it is recognition of the existence of different 'knowledge types'. These knowledge types, identified, for example, in the work of British sociologist Basil Bernstein (see, for example, 1999) and others (see, for example, Gamble, 2003, 2006), include 'applied' knowledge and 'professional knowledge'. Given the focus on the production of knowledge in postgraduate research, clearly this has implications for supervision. One account of 'applied knowledge' (Layton, 1993 cited in Gamble, 2006), for example, describes its production as resulting from reflection on theoretical knowledge as attempts are made to apply it in context. As will be seen from a perusal of the mission and vision statements of South African universities, the universities of technology and, to some extent, the comprehensive universities have taken up the idea of 'applied knowledge' with some enthusiasm. This clearly has implications for supervision which is contextually sensitive and for supervisors who can draw on a range of methodologies and approaches to research. If applied knowledge does indeed result from reflection on theoretical knowledge in practice, the research methodologies would need to incorporate a reflective component.

One final impact of shifts following the advent of democracy relates to the academic workforce. The need for universities to transform their staff profiles and the resulting competition to attract black academics with research profiles has already been noted earlier in this chapter. While black academics are in heavy demand, recruitment of 
a 'new generation' of academics has not matched growth in the higher education sector. Many established researchers and supervisors are now approaching the end of their working lives and questions about who is to replace them are becoming urgent. The need for individuals who have completed postgraduate work as academics is greater than ever but, even more pertinently, there is a need for those individuals to represent the greater demographics of the country. At the same time, the academic workplace has become less attractive to many as remuneration does not match what can be offered elsewhere while the demands on academics to perform all of the areas of scholarship identified by Boyer (1990) as well as to contribute to the running of their departments are perceived to be increasingly demanding.

The HEQSF noted earlier identifies the ability to supervise postgraduate research as one of the outcomes of a doctoral-level qualification. The assumption therefore seems to be that one can learn how to supervise simply by being supervised, a claim that those involved in the project underpinning this book, and described in the Foreword, would dispute most strongly. However, as the project has shown, it is not only the availability of formal courses intended to develop supervisory capacity that allow for quality supervision (McKenna and Boughey, 2014).

\section{THE CONTEMPORARY POSTGRADUATE ARENA AND SUPERVISION}

We began this chapter by stating that postgraduate supervision is a challenging form of teaching in any context and that it could be particularly difficult in contexts marked by disparities. Our account of the South African higher education system and the impact of policy on it since 1994 now lead us to the postgraduate arena, to a discussion of the inequalities by which it continues to be marked and the way these impact on postgraduate supervision.

Earlier in this chapter we noted the way historical inequities impacted on the capacity to engage with research in the different kinds of institutions under apartheid. To recap, the historically white universities were funded for research and encouraged to engage with it. This was not the case for the historically black universities. This impacted on the 'research cultures' and structures which developed in these different kinds of institutions, both of which were built over decades and sustained through practice. While policy since 1994 has attempted to promote research across all universities through financial incentives, this has not necessarily impacted on the development of research communities that can sustain and encourage research, researchers and, thus, supervisors of postgraduate work. An individual academic working in a historically white university would be likely to find herself immersed in a rich research culture where seminars, discussions and other fora all promoted 
intellectual engagement across a wide range of topics both within and without her own disciplinary area and specific research interest. The same academic might find herself serving on well-functioning higher degrees or ethical standards committees as a result of which she would read a large number of proposals to conduct research and would be guided by the discussions that took place in committee meetings to a deeper understanding of research methodologies and research issues. If the individual was a more junior member of staff, she might be mentored by her more experienced peers and could even be part of a cohort of junior researchers receiving funding and support to develop her own research trajectory and postgraduate programme. Her initial experiences of supervision might be of co-supervision where she would be inducted into supervisory practice by a peer.

Even in such research-rich contexts, however, a supervisor is likely to encounter challenges. Those students who present themselves for supervision and who are judged to be 'ready' or 'postgraduate material', might be drawn from particular social groups rather than represent the entire spectrum of diversity in South African higher education. Although support for supervision is available, those offering this support might only draw on experience of supervising particular kinds of students.

This experience might not be mirrored in other kinds of institutions, particularly the historically black universities and the universities of technology where efforts to establish or enhance research cultures are still in their infancy thanks to the efforts of newly appointed agents and newly developed structures intended to foster research. In such contexts, an academic might find that she is a 'lone' researcher or supervisor left to make decisions without the support of peers. She might be one of the few individuals within a department or subject area with a doctorate and thus her supervision load will be enormous regardless of her experience.

We have referred to the notion of 'research culture' several times in this chapter but institutional value and belief systems do not only impact on research. The historically white English-speaking liberal universities prized academic freedom and institutional autonomy throughout the years of apartheid and the liberties they guarded during this time survive to this day. This was not the case for the historically black institutions or the technikons which were both subject to much stronger control from the apartheid government, or for the Afrikaans-speaking historically white universities which, ideologically, were more disposed to control by a governance structure which supported apartheid. This historical conditioning impacts on management and governance in the different kinds of universities to this day. Culturally, some universities are disposed to a more managed approach to teaching, learning and research which often involves the use of performance management systems. In the 
area of postgraduate education, such an approach might involve students simply being allocated to a supervisor without any consultation about whether or not the researcher feels able to take on the study. Other universities are much more resistant to management with the result that a 'lighter touch' is used (McKenna and Boughey, 2014).

Since South Africa emerged from apartheid in the early 1990s, the need to engage with the globalised 'knowledge economy' has been paramount. A number of studies (see for example, ASSAf, 2010) and policy documents including the National Plan 2030 (RSA, 2012) identify the importance of postgraduate qualifications to economic development and thus to the future of the country. The ASSAf PhD Study outlines the position thus:

There is broad consensus in the scientific community that not enough high-quality PhDs are being produced in relation to the developmental needs of the country. Studies show a clear link between the economic wealth of nations and their 'citation intensity'. According to this analysis, South Africa is clustered with countries such as Poland, Russia and Brazil, and the Department of Science and Technology (DST) in its Ten Year Innovation Plan urges South Africa to increase its knowledge output substantially if it is to join the ranks of wealthier countries. Put differently, for South Africa to be a serious competitor in the global knowledge economy, both the quality and quantity of $\mathrm{PhDs}$ need to be expanded dramatically. The production of highquality $\mathrm{PhDs}$ requires both quality of input (e.g. supervision, facilities, environment, student) and quality of output - that is the graduate (ASSAf, 2010:21).

Currently, South Africa produces only about $28 \mathrm{PhDs}$ per million of the population (Cloete, Mouton and Sheppard, 2015), a figure that compares very unfavourably with other countries in a comparable economic position. Brazil, for example, produces 52 per million and, although figures are not available for China, the investment in higher education generally and in postgraduate study in particular, indicates an enormous drive to increase postgraduate production.

Interestingly, the ASSAf report notes the need to increase both the quantity and quality of $\mathrm{PhD}$ in South Africa. Quality is, of course, an elusive notion but, in this case, could refer to the need for methodologies and theoretical approaches to be cross-cutting and cutting edge alongside the need for work to be inter- and trans-disciplinary. Clearly, this has enormous implications for supervisors who need to guide postgraduate studies and who, depending on their own experiences at doctoral level, may not have been exposed to a wide range of methodological and theoretical approaches, a situation which is then exacerbated by the lack of 
a 'research culture' in the institutions in which they work which would contribute to their ongoing development.

\section{ENGAGING WITH SUPERVISORS, ENGAGING WITH CONTEXT}

Is it possible to do justice to all these complexities in a general course on postgraduate supervision that is offered across universities in South Africa? In a single course, is it possible to address the many contexts in which supervision takes place, ranging from the personal, to the institutional, to the disciplinary, to the political, to the historical? As individuals involved in the design of the course which brought the contributors of this book together, we were very aware of the danger of trying to make the course 'all things to all people'. We were also aware that any attempt to impose a 'blueprint of supervision' on our colleagues would not be sound and would be resisted by participants who, in any case, would be drawing on their own experience and expertise as supervisors working in the postgraduate arena. The course design team therefore approached its task with a hefty dose of humility with regard to what we could do and what we should do.

One of the earliest realisations of the course design team was that what we could do was facilitate in-depth conversations about what it means to do postgraduate supervision work which would not only allow participants to engage on the basis of their own experience, expertise and context but which would also allow them to decide to what to give attention and what to leave for another day. That is not to say that the course just drifted on the sentiments of groups of colleagues, but that there was a serious intention to create a space where people could speak up about their own experiences. Some of these experiences encompassed those of the participants as they themselves were 'under supervision' and how they imagined or practised their own supervisory practices as a result of it. This book draws on those conversations and the reflections they prompted as participants engaged with other parts of the experience offered by the course, including the assessment portion.

At this point, it is important to recognise that, in focusing on facilitating meaningful conversations, the course was not intended to be 'neutral' or 'innocent' in any way. Rather, it was a course with the explicit aim of prompting engagement with the tricky and contentious issues to be found in any context riven by inequality and disparities.

The first theme addressed in the very first hours of the very first day of the course involved power and social exclusion in supervision. Issues of gender, race, class, age, language, academic hierarchy, and all their intersectionalities were addressed directly in spite of the fact that participants may not yet be familiar with each other even though they work in the same institution. This overt confrontation with the 
power struggles that are played out on a daily basis in everyday life in South Africa, and not only in academic teaching spaces, was understood to be so important that it needed to be privileged 'upfront' as an issue in supervision. Some participants considered this sort of start to a course on supervision hard to swallow. By the end of the course, as feedback shows, many found addressing issues related to social exclusion and power at the outset set the tone for the course in an unequivocal way, and indicated their growing awareness that supervision is not 'something special' operating outside the broader socio-cultural processes in South Africa, but must rather be understood as a practice that is a microcosm of South African society.

In particular, participants from the Natural Sciences expressed their apprehension towards the concepts and language used to address issues related to social inclusion and power. Some even denied that such problems existed in their field. These levels of discomfort during the course were not ignored but openly discussed, using examples from different disciplines. Regardless of discipline, thinking about knowledge production is crucial with a focus on people involved in that process. It is important to work across disciplines, moving beyond Humanities and the Social Sciences only.

As we have tried to indicate, the goal of the course is to improve supervision in all universities in South Africa by offering opportunities to spend time thinking about issues, processes and approaches to supervising students. The need for supervisors to understand and develop their own scholarly identity is stressed throughout the course. If students themselves are to achieve the highest levels of scholarship in their own studies then they need to be guided by someone with a personal investment in such scholarship. As you will read in the various chapters in the book, there is a certain level of pride in having, nurturing and sustaining a scholarly identity, in being a scholar. A scholarly identity may be considered a professional identity, but for many academics it is closer to a particular lifestyle than anything else. As contributors to the project, and developers and facilitators of the course, what is evident to us is that the course has often prompted participants to consider their very 'being' in the academy as well as in society more generally.

In this chapter we have focused on the South African context in particular and the role the course on supervision which prompted this book has played in trying to address issues and problems found there. As the Preface to this volume indicates, the project on which the book was based involved collaboration between academics from Dutch and South African universities. The problems and issues we have indicated as relating to power and social inclusion must not be understood as uniquely South 
African problems as those involved in the project from the Netherlands ${ }^{1}$ will attest. Issues related to power and social inclusion are inscribed in all societies and require a direct and critical response.

\section{WHERE TO FROM HERE?}

As we write this introductory chapter, it is impossible to ignore the fact that the South African higher education system is in turmoil. The student protests of 2015 and 2016 not only called attention to the dire lack of state funding for the universities but also to the failure of the universities themselves to 'transform'. The decision, on the part of the State President, to impose a 0\% rise in tuition fees for the 2016 academic year has resulted in many universities having to employ austerity budgets and other measures to contain costs. The position for the future is still uncertain as the Presidential Commission appointed to investigate the possibility of free higher education will not report until 2017. The impact of austerity on budgets for research which sustain postgraduate education and supervision has yet to be seen. At the same time, transformation work is costly, requiring funding for scholarships and, sometimes, for the mentoring and support of new supervisors.

The calls for the 'decolonisation' of the curriculum in the protests of 2015 in particular obviously has implications for the course which prompted this volume and for those involved in developing and facilitating it. Project members all shared a strong belief in the need for a lifelong investment in a scholarly identity. From this perspective, the intellectual critique of the 'neoliberal university' and, particularly, of the business and management discourses that prevail at many universities was particularly meaningful. Even to speak of the 'production' of PhDs is disturbing in this context.

We were also mindful that the challenges to South African higher education are not unique. Universities across the rest of Africa also struggle to define their role in society, address the various challenges they are facing and set their research agenda (Zeleza and Oluksohi, 2004) and so too do universities elsewhere.

Mindful of the calls for universities to 'decolonise', the group called upon a colleague at Rhodes University, Corinne Knowles, a participant in one of the Strengthening Postgraduate Supervision courses, to write a reflective piece in a series entitled

1 See for instance http://www.universityworldnews.com/article. php? story = 20150313224103532; https://libcom.org/blog/student-protests-escalatingamsterdam-25022015; http://www.aljazeera.com/indepth/features/2015/05/dutchstudents-rebel-university-corporate-turn-150507063029643.html, (accessed 6 September 2016) 
'Points to Ponder' published within the course. In the piece, Knowles (2015:3) states clearly the position of those calling for change and its implications for supervision:

The internationalisation of Higher Education and HE studies has meant that the emerging intellectual conversations around $\mathrm{HE}$ practices and knowledge draw heavily on a western canon, which is establishing itself in the thinking on, for instance, supervision practices in South Africa. Scholars in this country have tended to work with and cite this canon in order to frame our orientations ... The coloniser's pedagogic framework has become part of who we are as thinkers and teachers, and is part of the content and terms of our conversations, as well as whom we inspire our postgraduates to become.

Rethinking supervisory pedagogy in the context of this challenge has to be an ongoing task - one which will be pursued as the course continues to be offered. As we have indicated repeatedly in this introduction, the intention was never for the course to impose anything on supervisors but rather to explore what could be possible through meaningful conversation. It is thus our hope that the course will generate knowledge about 'decolonised supervisory practices' as it continues to be offered. With this end in mind, we accept Knowles' (2015) challenge to include readings which provide 'an alternative view to the western ideas' in the course and trust that as our conversations continue so our understandings will grow and, importantly, we will be able to share those understandings with the rest of the world. This volume is but a small step in reaching this goal.

\section{REFERENCES}

Academy of Science of South Africa (ASSAf), 2010. The PhD Study. Pretoria: ASSAf.

Badat, S. (2010) The challenges of transformation in higher education and training institutions in South Africa, Development Bank of Southern Africa (accessible through: www.ru.ac. $\mathrm{za} / \mathrm{media} /$ rhodesuniversity/content/vc/documents/The\%20Challenges $\% 20$ of $\% 20$ Transformation\%20in\%20Higher\%20Eduaction\%20and\%20Training\%20Institutions $\% 20$ in\%20South\%20Africa.pdf), accessed 18 August 2016.

Bernstein, B. 1999. Vertical and horizontal discourse: An essay. British Journal of Sociology of Education. 20(2), 157-173.

Boyer, E. 1990. Scholarship reconsidered: Priorities of the professoriate. Stanford, CA: Carnegie Foundation for the Advancement of Teaching.

Cloete, N., Mouton, J. \& Sheppard, C. 2015. Doctoral Education in South Africa: Policy Discourse and Data. Cape Town: African Minds.

Cooper D. \& Subotsky, G. 2001. The Skewed Revolution: Trends in South African higher education, 1988 - 1998. Bellville: Educational Policy Unit, University of the Western Cape.

Council for Higher Education (CHE). 2002. Framework for Institutional Audits. Pretoria: CHE. 
Department of Education (DoE). 2001 a. National Plan for Higher Education. Pretoria: Department of Education.

Department of Education (DoE). $2001 \mathrm{~b}$. The restructuring of the higher education system in South Africa: Report of the National Working Group to the Minister of Education. Pretoria: Department of Education.

Department of Higher Education and Training (DHET). 2013. The Higher Education Qualifications Sub-Framework. Pretoria: DHET.

Gamble, J. 2003. Curriculum Responsiveness in the FET Colleges. Cape Town: HSRC Press.

Gamble, J. 2006. Theory and practice in the vocational curriculum. In Young, M. \& Gamble, J. eds. 2006. Knowledge, Curriculum and Qualifications for South African Further Education. Cape Town: HSRC Press.

Kamsteeg, F. 201 1. Transformation as social drama: Stories about merging at North West University, South Africa, Anthropology Southern Africa, 34 (1 \& 2), $51-61$.

Knowles, C. 2015. Reflections on the decolonization of knowledge in the Strengthening Postgraduate Supervision course, Points to Ponder, Strengthening Postgraduate Supervision, available at www.postgraduatesupervision.com

Layton, D. 1993. Science education and praxis: The relationship of school science to practical action. In E.W. Jenkins ed. School science and technology: Some issues and perspectives. London: Centre for Studies in Science and Maths Education.

McKenna, S. \& Boughey, C. 2014. Argumentative and trustworthy scholars: the construction of academic staff at research-intensive universities. Teaching in Higher Education, 19 (7), 825-834.

Moses, I. 1984. Supervision of higher degree students - Problem areas and possible solutions, Higher Education Research and Development, 3(2), 153-166.

Ministry of Education (MoE). 2004. A new funding framework: How government grants are allocated to public higher education institutions. Pretoria: Ministry of Education.

Ministry of Education 2013. The higher education qualifications sub-framework. Notice 1040 of 2012, Government Gazette 36003, 14 December 2012.

Republic of South Africa. 2012. National Development Plan, 2030: Our future, let's make it work. Pretoria: National Planning Commission.

Young, M. \& Gamble, J. eds. 2006. Knowledge, Curriculum and Qualifications for South African Further Education. Cape Town: HSRC Press.

Zeleza, P.T. \& Olukoshi, A. eds. 2004. African Universities in the twenty-first century. Volume II Knowledge and Society, Dakar: CODESRIA 